\title{
Local Versus Global Processing in Autism: Special Section Editorial
}

\author{
David R. Simmons ${ }^{1} \cdot$ Greta K. Todorova ${ }^{1}$
}

Published online: 27 January 2018

(c) Springer Science+Business Media, LLC, part of Springer Nature 2018

The idea for this special section of the Journal of Autism and Developmental Disorders came from a Scientific Panel which took place at the 2014 International Meeting for Autism Research in San Diego, CA, organized by Dr. Bart Boets, with one of us (Dr. David Simmons) as the Discussant. The panel, entitled "Towards an integrated neurocognitive account of local versus global processing in Autism Spectrum Disorders" was a consideration of the evidence in favour of "superior" local processing and/or "inferior" global processing in autism in the light of both our own general review of the literature on vision in Autism Spectrum Disorder (Simmons et al. 2009) and the more recent publication, from the Leuven group of which Dr. Boets was then a part, of a meta-analysis focused on the topic (van der Hallen et al. 2015).

Whilst Simmons et al. (2009) came down in favour of superior local processing ("... local superiority effects in tasks such as visual search seem to be holding their own", p. 2728), Van der Hallen et al. (2015) found strong evidence of publication bias in this literature which was obscuring a small-to-insignificant effect except in cases where the Dependent Variable was Reaction Time and the task was a "global" judgement in the presence of "local" distractors, such as one version of the well-known Navon task. Van der Hallen et al.'s (2015) analysis confirmed a suspicion expressed earlier on the same page of Simmons et al. (2009) that much of the data on vision and autism published between 2005 and 2009 was "... contradictory, or at least contested." A frustrating feature of much research on vision in ASD has been that a positive result showing a significant difference between autistic and some sort of control population published one year is almost inevitably followed by a failed replication as the "file drawer" opens, consistent with Van der Hallen et al.'s (2015) analysis. Ultimately, then,

David R. Simmons
David.Simmons@glasgow.ac.uk

1 School of Psychology, University of Glasgow, 58 Hillhead Street, Glasgow G12 8QB, UK all we learn is that ASD is a heterogeneous condition, and Boets' statement in the Panel abstract that "atypical visual processing cannot currently provide us with a reliable endophenotype for ASD" seems very much justified.

How did we get to this position? In addition to the issues with population heterogeneity and publication bias alluded to above, it is unfortunate that many studies of vision in ASD have lacked methodological rigour. There are numerous examples in the published literature of a failure to properly calibrate visual displays, failures to screen control groups for autistic traits (which are sometimes correlated with performance in perceptual tasks, see Robertson and Simmons 2013), poor matching of autistic and control populations and failures to double-check optical correction. Furthermore, sample sizes tend to be small, thus increasing the probability of finding spurious differences, and also tend to be drawn from the most "co-operative" groups within the autistic community, usually school-age males with typical IQ levels.

Whilst by no means perfect, the papers published in this special section go some way towards demonstrating what can be achieved. All papers have gone through the usual peer review process of the Journal and have been seen by specialists in the area with expert knowledge of both perceptual research AND autism. However, the research on display here indicates that there is still much work to be done.

Initial evidence that there was "local superiority" in autism came from the landmark paper of Shah and Frith (1983), followed up by Shah and Frith (1993), indicating "an islet of ability" in autism, whereby young people with autism showed superior performance in the well-known "embedded figures" and "block design" tasks. This result partly gave rise to the "Weak Central Coherence" (WCC) account of ASD which posited that there was a difficulty integrating context in autism at many levels of processing, including simple visuo-spatial tasks (Frith and Happé 1994). Early results about visual search superiority in autism (Plaisted et al. 1998) backed this up to some extent, although the similar-but-subtly-different "Enhanced Perceptual Functioning" (EPF) account suggested an alternative mechanism based on true local superiority rather than reduced global functioning 
(Mottron and Burack 2001). Both accounts seemed to be at one with first-hand reports of "fragmented worlds" and fascination with visual detail often reported (Frith 2003; Williams 1998). The papers in this special section by Booth and Happé (2017), together with a recent publication elsewhere in this journal by Guy et al. (2017) are sympathetic to what is now called "weak coherence" (Happé and Frith 2006) and the EPF accounts respectively and give up-to-date interpretations of them in the light of more recent findings, particularly as viewed through the lens of the Van der Hallen et al. (2015) meta-analysis. Interestingly, both studies confirm the finding of Van der Hallen et al. (2015) that the most robust difference between ASD and TD populations in this context is local-to-global interference in the temporal component of visual processing, although, in typical fashion for the field, a more-recent study by Van der Hallen et al. (2017b) has not confirmed this result in a larger group.

Van Eylen et al. (2017) provide a theoretically agnostic comparison of local versus global processing abilities in ASD and TD individuals using a battery of tests on a large, well-characterized group. Whilst some differences were found these were relatively subtle, especially in comparison to the large differences in "attention to detail" in daily life as reported by the parents/care-givers, and there were clear influences of task demands and participant characteristics (i.e. age and gender), further complicating interpretation of the results. Van der Hallen et al. (2017a) found no significant differences between the performance of ASD and TD groups in their "multiple object tracking" task, which was designed to probe abilities in perceptual grouping.

These papers emphasize that there is still an issue with definitions. When we say "local" do we mean occupying a small region of a perceptual domain, such as visual space or auditory frequency, or are we speaking of a more neural-level definition which considers a localized region of sensory cortex? And how are other variables like spatial frequency involved? Stevenson et al. (2017) consider this point and also extend the scope of the argument by looking at autistic traits, rather than a diagnosed population, and the effects on face perception. They also illustrate the malleability of the default level of processing (local or global) by priming tasks. Stewart, Griffiths and Grube (2017) also examine performance as a function of autistic trait level, but explore local versus global processing in the auditory domain, finding that both the discrimination of pitch and time-interval discrimination are correlated with trait level. Finally, in this special section, Maule et al. (2017) examine colour perception, finding that colour afterimages seem to be unaffected by the presence of an ASD diagnosis, despite theoretical reasons to expect the contrary.

Ultimately, the debate on local versus global processing in autism still goes on. The research presented here, whilst informing the debate, does not resolve it. Recent attempts to frame this debate in the larger "bottom-up" versus "top-down" processing story may bear fruit in the near future, especially as this also feeds into the theoretical battleground around "predictive coding" theories of ASD (e.g. Pellicano and Burr 2012; Van der Cruys et al. 2014; Lawson et al. 2014). Once again the Leuven group are leading the way here with a valiant attempt at integration in the recent papers of VanMarcke and co-workers, who has demonstrated how both WCC and EPF may be seen as "hierarchy perturbations" within the context of the Reverse Hierarchy Theory of Ahissar and Hochstein (2004) (e.g. VanMarcke et al. 2016, 2017). VanMarcke (2017) argues that, due to less-reliable meta-level or gist models of the environment, individuals with ASD show a less efficient (i.e. slower) early-stage and pre-attentive processing of global visual information, in accordance with WCC. On the other hand, this inefficient feed-forward processing of gist information coincides with a later-stage advantage in the attention-focused processing of local scene or object elements, in accordance with EPF. This results in individuals with ASD switching faster to a more detail-focused processing of a visual scene than typical individuals.

However, there is still a large explanatory gap between accounts of subjective perceptual experience and labbased measurements of perceptual performance which may never be bridged, despite the best efforts of Van Eylen et al. (2017) and Stevenson et al. (2017) presented here. One way forward, which we intend to explore, is matching up these two accounts more carefully in individual participants. This approach has the welcome side-effect of informing participants in more detail about their own perceptual idiosyncrasies and will potentially have some therapeutic consequences at the individual level as well as helping us to understand autistic perception in general better.

One final note is that the contribution of one group to the IMFAR symposium in 2014 is published elsewhere (Manning et al. 2015), and further contributes to the debate around local versus global processing of visual motion in ASD.

Acknowledgments Thanks go to Fred Volkmar, for authorizing this special section of the journal, Bart Boets for initiating the idea and all the anonymous referees who contributed to the debate while we put the collection together.

Author Contributions DRS was the editor for this special section, conceived the idea for the editorial and wrote the first draft. GKT performed the background research which informed the editorial, discussed the ideas included with DRS and amended the first draft to arrive at a consensus publication.

Funding Writing of this editorial was partially funded by a +3 studentship award from the Scottish Graduate School of Social Science of the Economic and Social Research Council, UK to GKT. 


\section{Compliance with Ethical Standards}

Conflict of interest Both authors declare that they have no conflicts of interest.

Ethical Approval This article does not contain any studies with human participants or animals performed by any of the authors.

\section{References}

Ahissar, M., \& Hochstein, S. (2004). The reverse hierarchy theory of visual perceptual learning. Trends in Cognitive Sciences, 8 , 457-464.

Booth, R. D. L., \& Happé, F. G. E. (2017). Evidence of reduced global processing in Autism Spectrum Disorder. Journal of Autism and Developmental Disorders. https://doi.org/10.1007/s1080 3-016-2724-6.

Frith, U. (2003). Autism: Explaining the enigma (2nd edn.). New York: Blackwell Science.

Frith, U., \& Happé, F. (1994). Autism: beyond "theory of mind". Cognition, 50, 115-132.

Guy, J., Mottron, L., Berthiaume, C., \& Bertone, A. (2017). A developmental perspective of global and local visual perception in Autism Spectrum Disorder. Journal of Autism and Developmental Disorders. https://doi.org/10.1007/s10803-016-2834-1.

Happé, F., \& Frith, U. (2006). The weak coherence account: Detailfocused cognitive style in Autism Spectrum Disorders. Journal of Autism and Developmental Disorders, 36, 5-25.

Lawson, R. P., Rees, G., \& Friston, K. J. (2014). An aberrant precision account of autism. Frontiers in Human Neuroscience, 8, 00302. https://doi.org/10.3389/fnhum.2014.

Manning, C., Tibber, M. S., Charman, T., Dakin, S. C., \& Pellicano, E. (2015). Enhanced integration of motion information in children with autism. The Journal of Neuroscience, 35, 6979-6986.

Maule, J., Stanworth, K., Pellicano, E., \& Franklin, A. (2017). Color afterimages in autistic adults. Journal of Autism and Developmental Disorders. https://doi.org/10.1007/s10803-016-2786-5.

Mottron, L., \& Burack, J. A. (2001). Enhanced perceptual functioning in the development of autism. In J. A. Burack, T. Charman, N. Yirmiya \& P. R. Zelazo (Eds.), The development of autism: Perspectives from theory and research (pp. 131-148). Mahwah, NJ: Lawrence Erlbaum.

Pellicano, E., \& Burr, D. (2012). When the world becomes "too real": A Bayesian explanation of autistic perception. Trends in Cognitive Sciences, 16, 504-510.

Plaisted, K., O'Riordan, M., \& Baron-Cohen, S. (1998). Enhanced visual search for a conjunctive target in autism: A research note. Journal of Child Psychology and Psychiatry, 39, 775-783.

Robertson, A. E., \& Simmons, D. R. (2013). The relationship between sensory sensitivity and autistic traits in the general population. Journal of Autism and Developmental Disorders, 43, 775-784.
Shah, A., \& Frith, U. (1983). An islet of ability in autistic children: A research note. Journal of Child Psychology and Psychiatry, 24, 613-620.

Shah, A., \& Frith, U. (1993). Why do autistic individuals show superior performance on the block design task? Journal of Child Psychology and Psychiatry, 34, 1351-1364.

Simmons, D. R., Robertson, A. E., McKay, L. S., Toal, E., McAleer, P., \& Pollick, F. E. (2009). Vision in Autism Spectrum Disorders. Vision Research, 49, 2705-2739.

Stevenson, R., Sun, S. Z., Hazlett, N., Cant, J. S., Barense, M. D., \& Ferber, S. (2017). Seeing the forest and the trees: Default local processing in individuals with high autistic traits does not come at the expense of global attention. Journal of Autism and Developmental Disorders. https://doi.org/10.1007/s10803-016-2711-y.

Stewart, M., Griffiths, T. D., \& Grube, M. (2017). Autistic traits and enhanced perceptual representation of pitch and time. Journal of Autism and Developmental Disorders. https://doi.org/10.1007/ s10803-015-2517-3.

Van der Cruys, S., Evers, K., Van der Hallen, R., Van Eylen, L., Boest, B., de -Wit, L., \& Wagemans, J. (2014). Precise minds in uncertain worlds: Predictive coding in autism. Psychological Review, 121, 649-675.

Van der Hallen, R., Evers, K., Brewaeys, K., Ven den Noortgate, W., \& Wagemans, J. (2015). Global processing takes time: A metaanalysis on local-global visual processing in ASD. Psychological Bulletin, 141(3), 549-573.

Van der Hallen, R., Evers, K., de-Wit, L., Steyeart, J., Noens, I., \& Wagemans, J. (2017a). Multiple object tracking reveals objectbased grouping interferences in children with ASD. Journal of Autism and Developmental Disorders. https://doi.org/10.1007/ s10803-015-2463-0.

Van der Hallen, R., Vanmarcke, S., Noens, I., \& Wagemans, J. (2017b). Hierarchical letters in ASD: High stimulus variability under different attention modes. Journal of Autism and Developmental Disorders, 47, 1854-1865.

Van Eylen, L., Boets, B., Steyeart, J., Wagemans, J., \& Noens, I. (2017). Local and global visual processing in Autism Spectrum Disorders: Influence of task and sample characteristics and relation to symptom severity. Journal of Autism and Developmental Disorders. https://doi.org/10.1007/s10803-015-2526-2.

VanMarcke, S. (2017). Perturbed cortical hierarchies in Autism Spectrum Disorder: The case of high-level vision. PhD Thesis: $\mathrm{KU}$ Leuven, Belgium.

VanMarcke, S., Van der Hallen, R., Evers, K., Noens, I., Steyeart, J., \& Wagemans, J. (2016). Ultra-rapid categorization of meaningful real-life scenes in adults with and without ASD. Journal of Autism and Developmental Disorders, 46, 450-466.

VanMarcke, S., van Esch, L., Van der Hallen, R., Evers, K., Noens, I., Steyeart, J., \& Wagemans, J. (2017). Gist perception in adolescents with and without ASD: Ultra-rapid categorization of meaningful real-life scenes. Research in Autism Spectrum Disorders, 29-30, 30-47.

Williams, D. (1998). Nobody nowhere: The remarkable autobiography of an autistic girl. London: Jessica Kingsley. 